\title{
Toxicogenomic evaluation of liver responses induced by acrylamide and glycidamide in male mouse liver
}

\author{
Dongyan Chen ${ }^{1}$, Huangyou Liu ${ }^{1}$, Enting Wang ${ }^{1,2}$, Haiyang Yan $^{1}$, Haiqing $\mathrm{Ye}^{1}$, Yuan Yuan ${ }^{1}$ \\ ${ }^{1}$ College of Food Science and Engineering, Jilin University, Changchun, China, 130062 \\ ${ }^{2}$ Chongqing Academy of Metrology and Quality Inspection, Chongqing, China, 401123
}

\begin{abstract}
In current studies, histopathologic method, Agilent GeneChip hybridization and Western blot were used to investigate the toxicity of acrylamide (AA) and glycidamide (GA) in male mouse livers. The histopathologic results demonstrated that AA and GA could cause oxidative damage to mouse liver. Middle dose of GA and AA ( $50 \mathrm{mg} / \mathrm{kg}$ b.w./day) could significantly up-regulate the expression of cytochrome P450, as well as genes related to oxidative injury, cancer and inflammation, and significantly down-regulate the expression of genes related to anti-apoptosis, antioncogene and fatty acid synthesis. Middle and high dose ( $75 \mathrm{mg} / \mathrm{kg}$ b.w./day) of GA and AA could both down-regulate the expression of hepatic anti-oncogene $\mathrm{Bcl} 2$ and up-regulate the expression of cancer-related gene Rad51 and EGFR protein. The expression of anti-oncogene P21 induced by AA and GA was decreased. Our current study demonstrated that the oxidative damage, immune injury and carcinogenicity of mouse liver samples could be induced by AA and GA at histopathological, entire genome and protein levels.
\end{abstract}

Key words: Aacrylamide - Glycidamide - Gene expression profile - Oxidative damage - Carcinogenesis

\begin{abstract}
Abbreviations: AST, aspartate aminotransferase; ALT, alanine aminotransferase; BUN, blood urea nitrogen; GSH, glutathione; LDH, lactic dehydrogenase; MDA, maleic dialdehyde; MPO, myeloperoxidase; ROS, reactive oxygen species; SOD, superoxide dismutase
\end{abstract}

\section{Introduction}

Acrylamide (AA) is a chemical monomer which is widely used in the synthesis of polyacrylamides in industry. Since 2002, researchers have shown that low levels of AA were found in carbohydrate-rich food during high-temperature processing such as frying, roasting and baking (Tareke et al. 2002). Toxicology studies showed that AA could cause neurotoxic and genotoxic damage to experimental animals (He 1989; Baum 2005; Manjanatha et al. 2006) and possessed the abilities to cause toxic effects on the development and reproduction (Dearfield et al. 1988) of rats and mice.

Through exposure treatment, AA can be rapidly distributed to all tissues and transformed into a more toxic form

Correspondence to:Yuan Yuan, College of Food Science and Engineering, Jilin University, Changchun, China, 130062

E-mail: yuan_yuan@jlu.edu.cn
- glycidamide (GA) by cytochrome P450 2E1(CYP2E1). Compared to wild-type mice, the levels of male germ cell mutagenicity, micronuclei, and GA-derived DNA adducts were much higher in CYP2E1-proficient counterparts, which indicated the importance of GA in the genotoxicity of AA (Ghanayem 2005a, 2005b). Other researches indicated that GA was the major genotoxic metabolite of AA (Manjanatha et al. 2006). The process that AA reacts with DNA occurs slowly (Solomon 1985), while, in contrast, the metabolite GA is considerably more reactive (Beland et al. 2013). The gene expression changed by AA or GA on nervous system, reproductive system or relative cell models were widely studied in recent publications (Camacho 2012; Chen and Chou 2015). Camacho et al. revealed that exposure to AA could cause the changes in testicular histopathology, gene expression, and serum hormones in male F344 rats (Camacho 2012). Early embryonic gene expression was affected by preconceptional paternal exposure to GA. Pa- 
ternal GA-exposure gave rise to an altered pattern of the expression of key DNA repair genes and genes important for embryo development, with an initially reduced expression at early stages followed by the increased expression at the 8-cell stage of the developing mouse embryo. After high concentration of GA exposure, GA induced typical markers of tumor progression such as steroid hormone activators, positive regulators of nuclear factor- $\kappa \mathrm{B}$, growth stimulators and apoptosis inhibitors (Brevik 2011). Concomitantly, the growth suppressors and cell adhesion molecules were down-regulated by the treatment of GA (Clement 2007). Transcriptional profiling of 542 mitochondria-related genes indicated a significant down-regulation of genes associated with the 3-beta-hydroxysteroid dehydrogenase family in AA- and GA-treated mice, suggesting a possible role of both chemicals in altering hepatic steroid metabolism in Big Blue mice (Lee 2012).

In our previous study, we evaluated the effects of AA and GA on mouse hepatocyte damages by hematological, biochemical and immunologic parameters (Wang et al. 2015). After exposure to AA or GA (50 mg/kg b.w./day), SOD, MPO, GSH and MDA levels in the kidney, liver, brain and lung tissues along with the AST, ALT, LDH, BUN, creatinine and ROS activities in the serum were significantly changed compared with the control groups. The immune-related cytokines IL-6, IL-1 $\beta$, TNF- $\alpha$ and IL-10 levels in the mouse serum also evaluated after treated by AA and GA. The present study discussed the effect of AA and GA exposure on the histological and genome wide transcriptional responses in the liver tissues, and mainly on the changes of the regulation of genes in liver and the expression of typical proteins induced by AA and GA.

\section{Materials and Methods}

\section{Materials and chemicals}

Acrylamide (AA) (CAS: 79-06-1, purity $>99.8 \%$ ) and glycidamide (GA) (CAS: 5694-00-8, purity $>99.0 \%$ ) were purchased from Sigma-Aldrich (St. Louis, MO, USA). Phenylmethanesulfonyl fluoride (PMSF) was purchased from Beyotime Biotechnology Co. Ltd (Jiangsu, China). The antibodies of $\mathrm{Bcl} 2$, Cdknla (P21), EGFR, actin and tubulin were obtained from Abcam Company (Cambridge, MA). Rad51 antibody was obtained from Cell Signaling Technology, Inc. (Beverly, MA). Peroxidase-conjugated goat anti-rabbit $\operatorname{IgG}(\mathrm{H}+\mathrm{L})$ antibody was obtained from Santa Cruz Biotechnology (Santa Cruz, USA). The sample loading-buffer and protein markers were purchased from Beijing DingguoChangsheng biotechnology Co. Ltd. (Beijing, China). Hematoxylin, neutral gum, paraffin, glycerin protein adhesive sheet, glycerol, eosin were obtained from Beijing DingguoChangsheng biotechnology
Co. Ltd. (Beijing, China). All the other chemicals were all of analytical grade or biological grade and purchased from Beijing Chemicals Co. (Beijing, China).

\section{Animals and experimental design}

Male BALB/c mice weighing $20 \pm 2 \mathrm{~g}$ were provided by the Laboratory Animals Center of Jilin University (Changchun, China). The experiments were performed in accordance with the Guidelines for Animal Experimentation of Jilin University (Changchun, China). Animals were housed in an air-conditioned room at $22 \pm 2{ }^{\circ} \mathrm{C}$ with a relative humidity of $30 \pm 10 \%$. The general conditions of the animals were observed during a quarantine and acclimation period of 7 days to confirm that there were no abnormalities.

After the quarantine period, 70 male mice were randomly divided into seven groups. Groups I, II, III and IV were control group, low dose AA group (25 mg/kg b.w./day, AA25), middle dose AA group (50 mg/kg b.w./day, AA50) and high dose AA group (75 mg/kg b.w./day, AA75), respectively. Groups V, VI and VII were low dose GA group $(25 \mathrm{mg} / \mathrm{kg}$ b.w./day, GA25), middle dose GA group (50 mg/kg b.w./day, GA50) and high dose GA group (75 mg/kg b.w./day, GA75), respectively. The control group was given saline by oral gavage for 30 consecutive days and the other groups were treated with AA or GA by oral gavage for 30 consecutive days. The body weights of the animals were measured daily. The doses of AA and GA were administrated according to the body weights of the animals.

After 30 days, liver samples were collected $24 \mathrm{~h}$ after the last exposure. The liver samples were washed thoroughly with ice-cold normal saline and stored at $-80^{\circ} \mathrm{C}$ for further analysis.

\section{Pathological analysis of the histological sections}

The same part of liver samples was collected and stored in formaldehyde for histological analysis. All images of histopathological analysis were collected under the same light intensity conditions. In order to ensure the comparability, the optical density was also carried out as the same batch. The histopathological diagnostic was used to evaluate the morphological changes of the mouse livers.

\section{RNA extraction and purification}

Total RNA was extracted with TRIZOL Reagent (Cat\#15596018, Life Technologies, Carlsbad, CA, USA) following the manufacturer's instructions. RNA integrity number was checked by an Agilent Bioanalyzer 2100 (Agilent Technologies Inc, Santa Clara, CA, USA). Only highly-qualified total RNA ( RIN $\geq 8.0$ ) was further purified with RNeasy mini kit (Cat\#74106, QIAGEN, GmBH, Germany) and RNase-Free 
DNase Set (Cat\#79254, QIAGEN, GmBH, Germany) were used for microarray of gene expression.

\section{Gene expression profiling analysis}

Liver tissues from mice treated with middle dose of GA and AA were selected to investigate the gene changes using a gene expression profiling method. The gene expression experiment was performed using the Agilent Whole Mouse Genome Oligo Microarray (Agilent Technologies Inc, Santa Clara, CA, USA). RNA amplification and labeling, GeneChip hybridization and microarray data acquisition and processing were provided by Shanghai Biotechnology Corporation (Shanghai, China), a service provider authorized by Agilent Inc. (Agilent Technologies Inc, Santa Clara, CA, USA). Three of the 10 mouse liver samples were selected randomly to investigate the gene changes as the replicates. The slides were scanned by Agilent Microarray Scanner (Cat\#G2565CA, Agilent technologies, Santa Clara, CA, USA) with default settings (Dye channel: Green, Scan resolution $=3 \mu \mathrm{m}, 20$ bit). Data were extracted with Feature Extraction software 10.7 (Agilent technologies, Santa Clara, CA, USA). Raw data were normalized by the Quantile algorithm in Gene Spring Software 11.0 (Agilent Technologies Inc, Santa Clara, CA, USA). To select the differentially expressed genes, threshold values were set from 1-fold to 6-fold changes between GA- or AA-treated samples and the controls.

\section{Protein extraction and Western-blotting}

Liver tissues (50 100 mg) were homogenized in the glass homogenizers on ice bath with $1 \mathrm{mM}$ of PMSF. Protein concentration was determined by BCA protein assay kit according to the manufacturer's recommendations (Beyotime Biotechnology, Jiangsu, China). Equal amounts of whole protein were denatured at $100^{\circ} \mathrm{C}$ for $3 \mathrm{~min}$ and separated by SDS polyacrylamide gel electrophoresis (PAGE). The proteins were transferred to a polyvinyl difluoride (PVDF) membrane (XLL092-2, PALL, US) by means of electrotransfer and the blots were blocked with 5\% skimmed milk powder dissolved in Tris-buffered saline containing $0.1 \%$ Tween 20 (TBST) for $120 \mathrm{~min}$ at room temperature. Membranes were then incubated overnight at $4^{\circ} \mathrm{C}$ with the primary antibodies against EGFR, P21, Bcl2, Rad51, $\beta$-actin and $\beta$-tubulin, respectively. Washed twice with TBST and once with TBS, the membranes were then incubated with peroxidase-conjugated secondary antibodies for $120 \mathrm{~min}$ at room temperature and washed twice with TBST and once with TBS. Immuno reactive protein was visualized by the BeyoECL plus kit (Beyotime biotechnology, Jiangsu, China). The analyses were carried out 5 times to confirm the results $(n=5)$. Band intensities were quantified by Quantity One software (Bio-Rad, USA).

\section{Statistical analysis}

Experimental data were analyzed with Origin 8.5 software (OriginLab, USA). The significant differences were determined using one-way ANOVA analysis. Differences with a $p$ value of $<0.05$ were considered statistically significant.

\section{Results}

\section{Effects of $A A$ and GA on hepatic histomorphology in mice}

Hematoxylin and eosin (HE) staining analysis was used to evaluate the effects of AA and GA on hepatic morphology. The appearance of the liver in the healthy control group was bright red, soft and elastic. Dark red color of the liver tissue was observed after treatment with high dose of AA and GA (Fig. 1). As shown in Figure 1, a central vein ran through the middle of the hepatic lobules and was surrounded by cords of liver cells which radiated out in all directions in the control group. In the liver blood sinus, there was 1 2 full light blue nucleuses locating in the center of liver cells, and the pink cytoplasm can be seen clearly. In the group treated with low dose of AA and GA (AA25 and GA25 group), no significant difference was observed from the appearance of the liver tissues compared with the control group. After being treated with middle dose of GA (50 mg/kg b.w./day), liver cells displayed unclear line arrangement in the hepatic lobule and inflammatory cell infiltration was occasionally observable, aswas observed obviously in AA treatment at the same dose (50 mg/kg b.w./day).In high dose of AA (75 mg/ $\mathrm{kg}$ b.w./day), liver cytoplasm light colored area was observed obviously in the large central vein in the liver tissue. And in high dose group of GA, focal inflammatory cells were found in the hepatic lobules, and the liver cells were full of shapes. Compared with the control group, the liver samples treated with middle and high dose of AA and GAshowed different degrees of damagesin a certain dose-dependent manner (Fig. 1). With the increase of AA and GA dose, the infection extent of liver cells by inflammatory cells was gradually expanded.

\section{General effects of $A A$ and $G A$ on gene expression in mouse livers}

The effects of mouse liver tissues treated with $50 \mathrm{mg} / \mathrm{kg}$ b.w./day AA revealed that a substantial number of genes (2817) were differentially regulated. Of the 2817 differentially expressed genes, 1369 genes were up-regulated and 1448 genes were down-regulated. Compared to the control group, 2510 genes were differentially regulated in mouse livers treated with GA at a dose of $50 \mathrm{mg} / \mathrm{kg}$ b.w./day. Of the 2510 differentially expressed genes, 1271 genes were up-regulated and 1239 genes were down-regulated. 


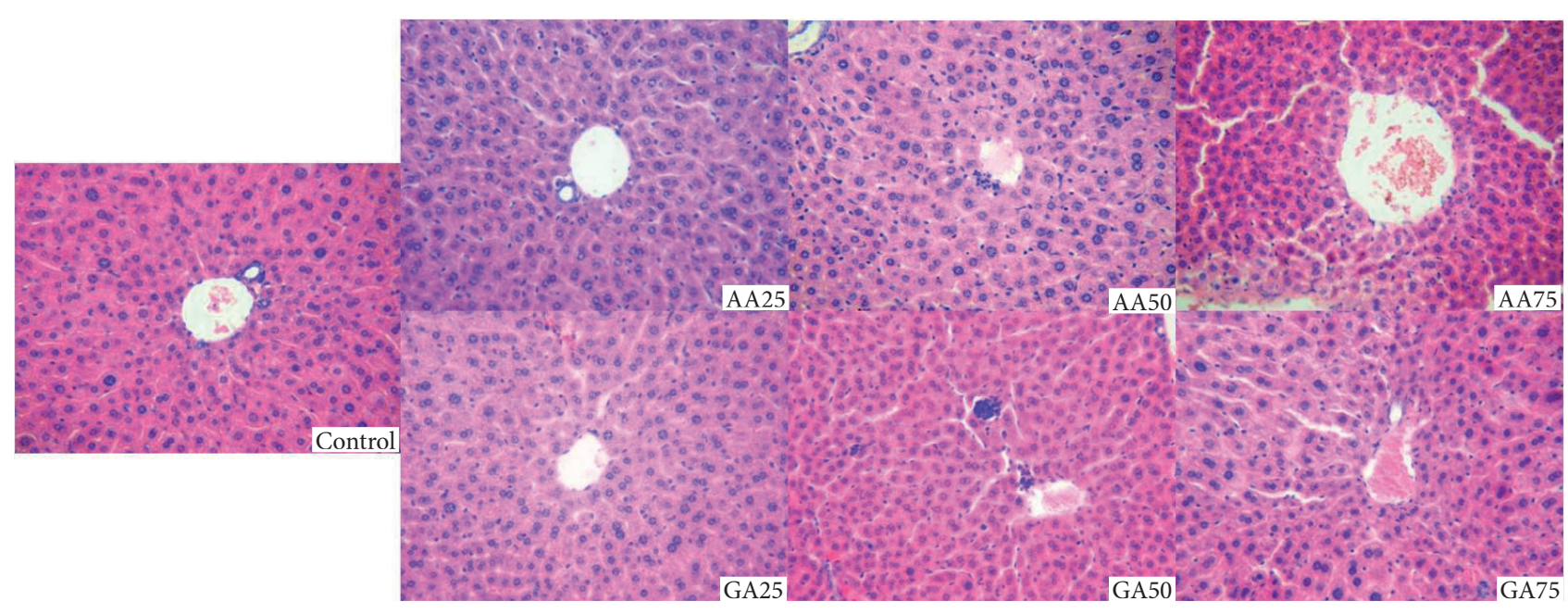

Figure 1. Effects of acrylamide (AA) and glycidamide (GA) on hepatic morphology (400x) in mouse livers. Notes: 1) GA25 and AA25: No significant difference was observed from the appearance of the liver tissues compared with the control group; 2) GA50 and AA50: Liver cell line arrangement was not clear in the hepatic lobule and inflammatory cell infiltration was observed occasionally; 3) GA75: Focal inflammatory cells infiltration could be observed obviously, with the form of hepatocyte full; 4) AA75: liver cytoplasm light colored area was observed obviously in the large central vein in the liver tissue.

Among all the altered genes influenced by AA and GA, the common 3-fold up-regulated GA-and AA-treated genes were mainly of the following categories: cytochrome P450related genes (Cyp2b13, Cyp39a1 and Cyp4a14), tumor and cancer-related genes (Myc, Rad51l1, Gadd45g, EGFR and Fg11), genes related to inflammatory diseases and regulation of inflammation (Orm3, Socs2, Cish, saa2 and Saa1), metallothionein-related genes ( $M t 1$ and $M t 2)$, and gene related to cationic transport regulation factor (Chacl). Meanwhile, the common 3-fold down-regulated genes were mainly of the following categories: anti-apoptosis-related gene (Bcl6), cancer-and tumor-related genes (Nnmt, Dmbt1, Lama3 and car3), fatty acid synthesis-related genes (FASN and Acly) and other genes (Thrsp, Mmd2, Gpam, Fbxw13 and Mvd).

In order to confirm the regulation of AA and GA on oxidative stress injury-, immune injury- and cancer-related genes, we searched the $\geq 3$-fold differentially expressed genes and found that the up-regulated genes related to oxidative stress injury induced by AA and GA were mostly associated with the cytochrome P450 metabolism, which was closely related to the transformation process from AA to GA and the oxidative stress injury induced by GA. Otherwise, the down-regulated genes related to oxidative stress injury were mostly associated with the regulation of anti-cell apoptosis and anti-tumor.

Genes with more than three-fold changes that are related to immune injury and cancer on signaling pathway induced by AA and GA were listed in Table 1 . We found that AA and GA treatment could mainly co-regulate genes in the cancer pathways, janus kinase-signal transducer and activator of transcription (Jak-STAT) pathways and mitogen-activated protein kinase (MAPK) pathways, which indicated the procedures of oxidative stress damage, immune injury and cancer of liver tissues induced by AA and GA.

\section{Effects of $A A$ and $G A$ on the expression of Bcl2, Rad51, Cdkn1a (P21) and EGFR protein in mouse livers}

In order to demonstrate the mechanism of oxidative stress damage and carcinogenesis induced by AA and GA, four genes related to oxidative stress damage and carcinogenesis were chosen for further study. A Western-blot method was used to investigate the expression of Bcl2, Rad51, Cdknla (P21) and EGFR. The $\beta$-actin and $\beta$-tubulin were used as a reference protein. Compared to the control group, the expression of Bcl2 significantly decreased in both $\mathrm{AA}$-and GA-treated groups (Fig. 2A). The expression of Bcl2 in GAtreated liver was higher than that of AA group at the same dose. The decrease of Bcl2 expression in high dose of GA group ( $75 \mathrm{mg} / \mathrm{kg}$ b.w./day) was about $49.24 \%$ compared to the control group, which was the highest of all the treated liver tissues. As for Rad51 protein, middle $(50 \mathrm{mg} / \mathrm{kg}$ b.w./ day) and high (75 mg/kg b.w./day) doses of GA could upregulate its expression by $4.99 \%$ and $14.68 \%$, respectively, while middle ( $50 \mathrm{mg} / \mathrm{kg}$ b.w./day) and high $(75 \mathrm{mg} / \mathrm{kg}$ b.w./ day) doses of AA could increase the expression of Rad51 by $4.19 \%$ and $6.16 \%$, respectively (Fig. 2B). However, low ( 25 $\mathrm{mg} / \mathrm{kg}$ b.w./day) dose of AA and all dose of GA didn't lead to any considerable changes in the expression of $\mathrm{P} 21$ protein ( $p>0.05$, Fig. 2C). And middle and high dose of AA down- 
Table 1. Three-fold change gene profiles of immune injury and cancer on signaling pathway induced by AA and GA

\begin{tabular}{|c|c|c|c|c|}
\hline \multirow{2}{*}{$\begin{array}{l}\text { Gene to } \\
\text { pathway }\end{array}$} & \multicolumn{2}{|c|}{ Acrylamide (AA) } & \multicolumn{2}{|c|}{ Glycidamide (GA) } \\
\hline & $\geq 3$-fold increase & $\geq 3$-fold decrease & $\geq 3$-fold increase & $\geq 3$-fold decrease \\
\hline Cancers & Igf1, EGFR, Myc & E2f2, Lama3, Msh3 & $\begin{array}{c}\text { Cdkn1a,Igf1,Fgf21Egfr, } \\
\text { Myc, Rad511 }\end{array}$ & E2f2, Lama3 \\
\hline ErbB Signaling pathway & $E G F R, M y c$ & & Cdkn1a,EGFR, Myc & \\
\hline $\begin{array}{l}\text { Erk1/Erk2 } \\
\text { MAPK Signaling pathway }\end{array}$ & $M y c, E G F R$ & Gngt1 & $E G F R, M y c$ & \\
\hline $\begin{array}{l}\text { Jak-STAT } \\
\text { Signaling pathway }\end{array}$ & $\begin{array}{c}\text { Cish, Socs2, Socs3, EGFR, } \\
M y c\end{array}$ & & $\begin{array}{c}\text { Cish, Socs2, } \\
\text { Socs3, EGFR, Myc }\end{array}$ & \\
\hline $\begin{array}{l}\text { MAPK } \\
\text { Signaling pathway }\end{array}$ & $\begin{array}{c}\text { Map3k6, Cacna2d1, Gadd45g, } \\
\text { Dusp2,EGFR, Myc } \\
\end{array}$ & Hspb1 & $\begin{array}{c}\text { Gadd45g, Il1r1, } \\
\text { EGFR, Myc }\end{array}$ & $\begin{array}{c}\text { Hspa1b, Bdnf, } \\
\text { Cacng2, Hspa1a } \\
\end{array}$ \\
\hline NF- $\kappa B$ Signaling pathway & & $H 2-K 1$ & $C d k n 1 a, I l 1 r 1$ & \\
\hline p53 Signaling pathway & Igf1,Gadd45 & & Cdkn1a,Igf1, Gadd45g & \\
\hline
\end{tabular}

regulated the expression of $\mathrm{P} 21$ in mouse livers by $9.28 \%$ and $60.71 \%$, respectively. After AA and GA exposure, the expression of EGFR in mouse liver tissues increased obviously (Fig. 2D). The expression of EGFR in high (75 mg/kg b.w./day) dose of AA group was 4.41 times higher compared to the control group, and that of middle $(50 \mathrm{mg} / \mathrm{kg} \mathrm{b.w./day)} \mathrm{dose}$ of GA group was 4.20 times compared to the control group.

\section{Discussion}

AA is widely used in various industrial fields and is found at concentrations of up to $3.5 \mathrm{mg} / \mathrm{kg}$ in some thermally treated starchy foods (Tareke et al. 2002). With a neonatal mouse bioassay it showed that intraperitoneally injected GA induced hepatocellular tumors with an incidence of $71.4 \%$ at a concentration of $0.70 \mathrm{mmol} / \mathrm{kg} . \mathrm{bw} /$ day. Since neonatal mice were deficient in monooxygenase CYP2E1 activity, the authors suggested that the carcinogenicity of AA was dependent on its metabolism to GA (Von Tungeln et al. 2012). Studies and reviews have reported the genotoxicity of AA and its metabolite GA (Besaratinia and Pfeifer 2007). Compared to AA, GA was mutagenic even at a dose of $2 \mathrm{mmol} / \mathrm{ml}$, which suggested that GA was much more mutagenic than AA in experimental animals. The studies presented here focused on the effects of AA and GA on the liver to understand better the potential for oxidative damage and carcinogenic effects of chronic AA and GA exposure.

Reports showed that AA and GA induced robust responses in DNA damage in liver cells of rodents (Von Tungeln et al. 2012; Zhao 2015; Dobrovolsky et al. 2016). As is well known, liver is the main tissue for metabolism and detoxification. In the process of xenobiotics phase I metabolism, cytochrome P450 enzyme system in liver microsomal released reactive oxygen intermediates, resulting in hydrogen peroxide and superoxide produced (Venkatakrishnan 2001), in which the process of AA to GA was accomplished. Our histomorphological study found apparent and visible oxidative damages in liver tissues of mice treated with middle $(50 \mathrm{mg} / \mathrm{kg} \mathrm{b.w./}$ day) and high (75 mg/kg b.w./day) doses of GA and AA. Additionally, the visible damage of liver tissues was dosedependent. Therefore, the liver tissues were selected for further investigation of carcinogenesis induced by GA and AA.

Close relationships among the occurrence of oxidative stress, inflammation and tumor were observed in some literatures. Oxidative stress could activate multiple transcription factors such as AP-1, p53 and Nrf2, including growth factors, inflammatory cytokines, chemokines, cell cycle regulatory molecules and the occurrence of antiinflammatory molecules and inflammation (Devi et al. 2015; Chechushkov et al. 2016; Wang et al. 2016). Usually, the inflammatory pathways activated by the oxidative stress can lead to the transformation of the normal cells to tumor cells, and promote tumor cell survival, proliferation and invasion, which ultimately lead to the occurrence of cancer (Reuter 2010).Our previous studies confirmed the results of the oxidative damage, immune injuries and carcinogenesis induced by AA and GA from evaluating hematological, biochemical and immunological markers (Wang et al. 2015). In our present study, 3-fold changed genes induced by AA and GA further strengthened the evidence of increase of MDA and MPO levels and decrease of SOD, GST and GSH levels in mouse livers in our previous data (Wang et al. 2015), which proved the oxidative damage and immune injuries induced by AA and GA at the level of the entire genome. Additionally, we found that 1 6-fold of significant differential genes responded more intensively to AA than to that of GA in the mouse liver tissues, and most genes regulated by GA were overlapped to genes regulated by AA. The co-regulated genes of AA and GA treatment of mice could destroy the stability and structure of cells and increase the cell apoptosis as well as 
A

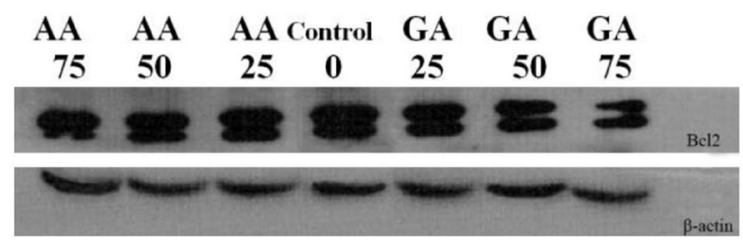

B

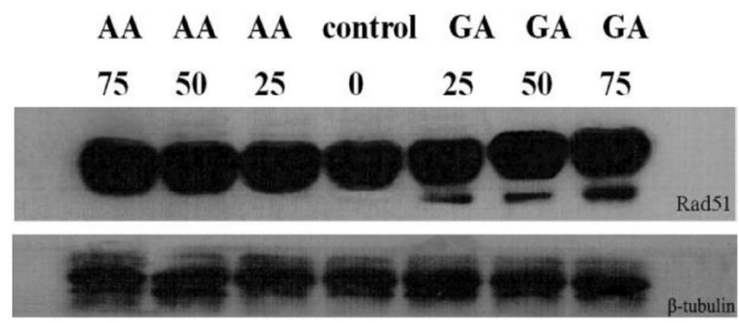

C

$$
\begin{array}{lllclll}
\text { AA } & \text { AA } & \text { AA } & \text { control } & \text { GA } & \text { GA } & \text { GA } \\
75 & \mathbf{5 0} & \mathbf{2 5} & \mathbf{0} & \mathbf{2 5} & \mathbf{5 0} & \mathbf{7 5}
\end{array}
$$

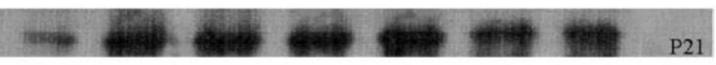

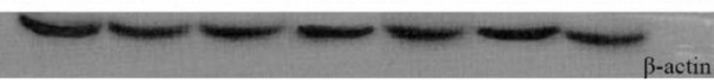

$\beta$-actin

D

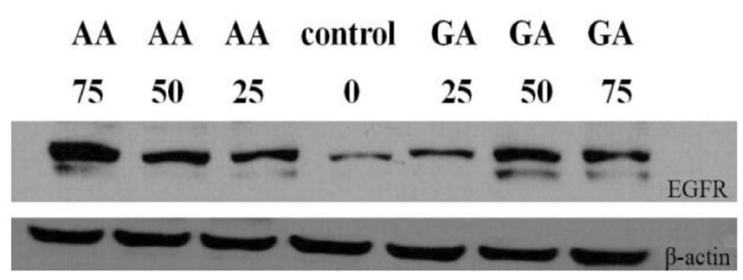

A

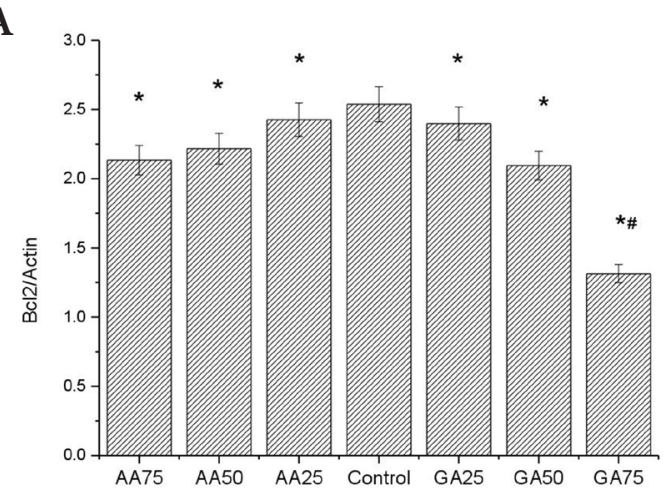

B

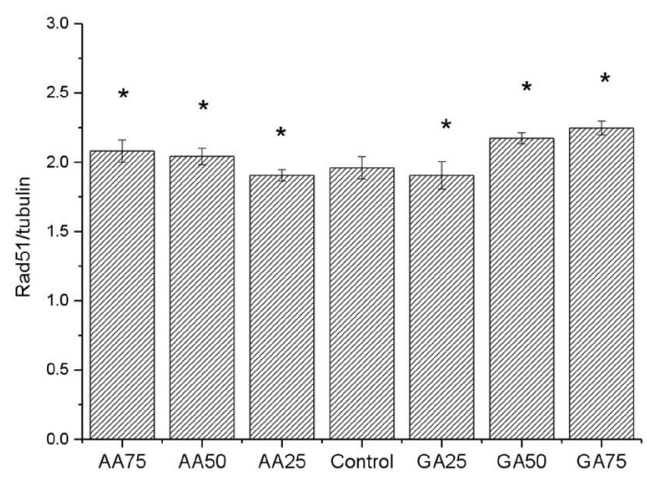

C

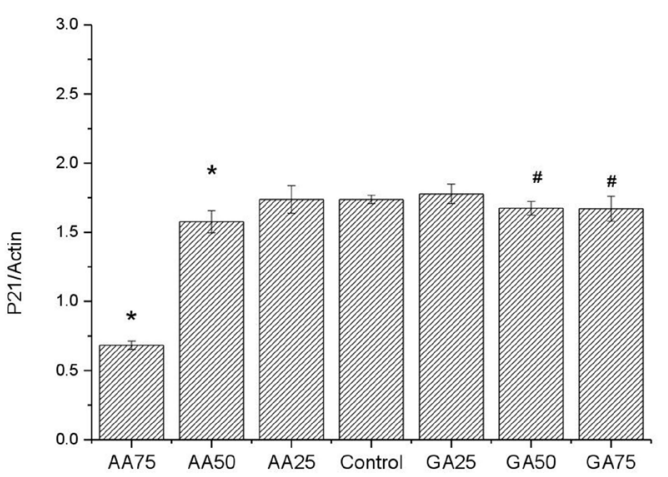

D

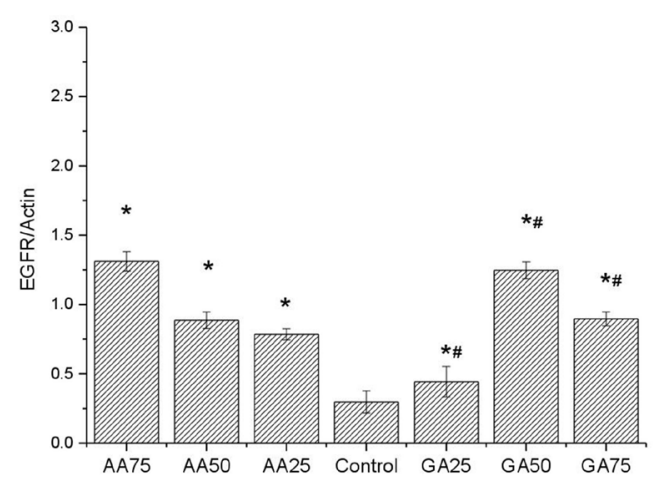

Figure 2. The influence of acrylamide (AA) and glycidamide (GA) on the expression of Bcl2, Rad51, P21 and EGFR. Representative Western-blot showing protein expression of Bcl2 (A), Rad51 (B), P21 (C) and EGFR (D). Data were presented as the mean \pm SD for 5 measurements in each group $(n=5)$; ${ }^{*}$ significant differences with control group $(p<0.05)$; \# significant differences of GA compared with the same doses of AA $(p<0.05)$. 
induce the inflammation and tumors. These results indicated that the regulation of the overlapping genes by AA might have close correlations to GA.

In our current study, representative proteins $(\mathrm{Bcl} 2$, Rad51, P21 and EGFR) related to the differential genes of immune injury and cancer signaling pathways were selected to study the mechanism of potential carcinogenesis induced by AA and GA. References have reported that ROS-mediated MAPK activation proved to be responsible for $\mathrm{Bcl} 2$ and Rad51 down-regulation (Lu et al. 2012; Changchien et al. 2015). Furthermore, the regulation of P21 protein through MAPK pathway and Jak-STAT pathway were certified to have relationships with cancer (Zhang et al. 2012). The expression of EGFR could be regulated through the Jak-STAT pathway by EGFR inhibitors, as is reported in many studies (Hu et al. 2016; Sun et al. 2016). What's more, the crosstalk between MAPK and Jak-STAT signal cascades regulates cellular functional events by stimulation of cytokines and growth factors (Eulenfeld 2012). Chen and Chou (2015) reported that AA could cause a down-regulation of the Jak-STAT signaling pathway in human neuroblastoma and glioblastoma cells and the MAPK pathway was important in the regulation of AA-induced cytotoxicity, which was conformed with our current results.

$\mathrm{Bcl} 2$ is a proto-oncogene, which can prevent the cell apoptosis induced by oxidizing agents and inhibit the occurrence of cancer (Korsmeyer 1993). The expression of $\mathrm{Bcl} 2$ could reduce the generation of oxygen free radicals and lipid peroxide $v i a$ the inhabitation to cytochrome $\mathrm{C}$ releasing (Pardhasaradhi 2003; Shen et al. 2003).This could prevent the formation of superoxide anion rather than scavenge the active. Bcl 2 could also increase some intracellular antioxidants such as GSH, and increase the ratio of NAD/NADH (Shen et al. 2003).The inhabitation to the reduction of GSH could promote the entrance of GSH into the cell nucleus. The redox state of cell may thus changes (Vogler et al. 2009).Our previous studies have confirmed that the ROS levels both in AA- and GA- treated mice were twice higher than that of the control groups $(p<0.05)$. Meanwhile, the contents of GSH both in AA- and GA-treated mice were much lower than that of the control group ( $p<0.05)$ (Wang et al. 2015). The present results further validated the oxidative stress injuries of the liver samples and reduction of vitality level of antioxidants induced by AA and GA at protein level. Lakshmi et al. (2012) studied that AA induced oxidative stress and neuronal apoptosis in cerebral cortex and also found that AA downregulated the expression of $\mathrm{Bcl} 2$ in rats. Simultaneously, we found that the dose of AA and GA showed a negative correlation with $\mathrm{Bcl} 2$ expression. The mitochondrial pathway of apoptosis is controlled and regulated by the $\mathrm{Bcl} 2$ family protein (Kelekar 1998). The results were consistent with the expression of $\mathrm{Bcl} 2$ in the current study. Our results showed that GA could significantly prevent $\mathrm{Bcl} 2$ expression. Thus more superoxide anions were produced, which caused the oxidative stress injury of liver and cell apoptosis. The excessive formation of superoxide anions could stimulate the oxidative damage of DNA.

Rad51 is an attractive target for anticancer drugs, high Rad51 levels are frequently observed in many human tumors and associated with increased resistance to DNA doublestrand breaks (DSBs) -inducing chemotherapeutics (Lu et al. 2012). In the homologous recombinational repair (HRR) pathway, Rad51 catalyzes the homologous pairing between single-stranded DNA (ssDNA) and double-stranded DNA (dsDNA), which is the central step of the HRR pathway (Takaku et al. 2011). In our current study, the middle and high dose of AA and GA treatment could significantly cause the increase of Rad51 expression. These results suggested that AA and GA evidently affected the efficiency of DNA repair and the stability of genes. Rad51 has high expressions in several kinds of tumor, including breast cancer, ovarian cancer, laryngocarcinoma and lung cancer, etc. (Klein 2008). The results of the expression of Rad51 and Bcl 2 showed that both AA and GA could cause oxidative stress in the liver and lead to cancer potentially.

In the early stage of the body's DNA repair ability, the body starts its own immune mechanism and inhibits the occurrence of injury. P21 protein is an important regulatory protein. In normal cells, P21 is a typical anti-oncogene which is induced by P53 and then prevents the copy of DNA and enhances the DNA repair (Waga 1994). In our study, we found that middle and high dose of AA could decrease the expression of P21 in mouse liver samples. Our results showed that lower expression of P21 is associated with the progression and malignancy of tumors. However, GA didn't have obvious influence on the expression of P21. Kim et al. (2015) reported that the expression of P21 was considerably increased in both AA-treated and GA-treated macrophages, indicating that $\mathrm{AA}$ and its metabolite appear to promote the same effects on cellular senescence and that AA could promote cellular senescence in vivo. Further mechanism of hepatotoxicity of AA and GA through P21 pathway is still under investigation.

EGFR (epidermal growth factor receptor) is involved in many pathways related to cancer in vivo The most common way is that it could activate the Ras protein by dimerization and lead to the phosphorylation cascade and then stimulate the PI3K/Akt signaling pathway (Ono and Kuwano 2006). It has been proved that the expressions and functions of EGFR have abnormities in several kinds of human tumor issues and tumor cell lines (Bourouba 2011; Hwangbo 2013). Data presented in Shan et al. (2014) demonstrated that low dose of AA was able to increase the proliferation of HepG2 cells through up-regulating EGFR expression. In our present study, we also found that the expression of EGFR was significantly increased by the participation of AA and GA 
at middle and high dose treatment. It could be evidence that AA and GA had inflammatory damage in mouse livers and a potential carcinogenesis. To our knowledge, this is the first report demonstrating that both AA and GA could decrease the expression of anti-oncogene $\mathrm{Bcl} 2$ and increase the expression of certain cancer positive-related factors, Rad51 and Efgr. Moreover, AA is able to down-regulate the anti-oncogene P21 while GA does not have an obvious effect on this protein.

In conclusion, AA and GA have visible effects on oxidative damage in mouse liver tissues. On histopathologic level, we found that middle and high dose of AA and GA could cause inflammatory cell infiltration in liver samples, which indicated the specific oxidative damages to mouse livers induced by AA and GA. Middle dose of AA and GA could significantly up-regulate cytochrome P450, oxidative injury-related and cancer and inflammation-related gene. Meanwhile, AA and GA could also down-regulate the expression of genes related to anti-apoptosis, antioncogene and fatty acid synthesis. AA and GA could both down-regulate the hepatic anti-oncogene $\mathrm{Bcl} 2$ and up-regulate the cancer-related gene Rad51 and EGFR protein. AA could decrease the expression of anti-oncogene P21 while GA showed a less significant effect on P21 protein. The ongoing research will be more focused on the specific relationship between hepatotoxicity induced by AA and GA.

Acknowledgement. This work was supported by the National Natural Science Foundation of China [31571939, 31471666], National Science Foundation of Jilin Province [20150101119JC], and Graduate Innovation Fund of Jilin University (2017119).

\section{References}

Baum M, Fauth E, Fritzen S, Herrmann A, Mertes P, Merz K, Rudolphi M, Zankl H, Eisenbrand G. (2005): Acrylamide and glycidamide: genotoxic effects in V79-cells and human blood. Mutat. Res. 580, 61-69

https://doi.org/10.1016/j.mrgentox.2004.11.007

Beland FA, Mellick PW, Olson GR, Mendoza MC, Marques MM, Doerge DR (2013): Carcinogenicity of acrylamide in B6C3F(1) mice and F344/N rats from a 2-year drinking water exposure. Food Chem. Toxicol. 51, 149-159 https://doi.org/10.1016/j.fct.2012.09.017

Besaratinia A, Pfeifer GP (2007): A review of mechanisms of acrylamide carcinogenicity. Carcinogenesis 28, 519-528 https://doi.org/10.1093/carcin/bgm006

Bourouba M, Benyelles-Boufennara A, Terki N, Baraka-Kerboua E, Bouzid K, Touil-Boukoffa C (2011): Epidermal growth factor receptor(EGFR) abundance correlates with p53 and Bcl-2 accumulation and patient age in a small cohort of North African nasopharyngeal carcinoma patients. Eur. Cytokine Netw. 22, 38-44
Brevik A, Rusnakova V, Duale N, Slagsvold HH, Olsen AK, Storeng R, Kubista M, Brunborg G, Lindeman B (2011): Preconceptional paternal glycidamide exposure affects embryonic gene expression: single embryo gene expression study following in vitro fertilization. Reprod. Toxicol. 32, 463-471 https://doi.org/10.1016/j.reprotox.2011.09.005

Camacho L, Latendresse JR, Muskhelishvili L, Patton R, Bowyer JF, Thomas M, Doerge DR (2012): Effects of acrylamide exposure on serum hormones, gene expression, cell proliferation, and histopathology in male reproductive tissues of Fischer 344 rats. Toxicol. Lett. 211, 135-143 https://doi.org/10.1016/j.toxlet.2012.03.007

Changchien JJ, Chen YJ, Huang CH, Cheng TL, Lin SR, Chang LS (2015): Quinacrine induces apoptosis in human leukemia K562 cells via 338 MAPK-elicited BCL2 down-regulation and suppression of ERK/c-Jun-mediated BCL2L1 expression. Toxicol. Appl. Pharm. 284, 33-41 https://doi.org/10.1016/j.taap.2015.02.005

Chechushkov A, Zaitseva N, Vorontsova E, Kozhin P, Menshchikova E, Shkurupiy V (2016): Dextran loading protects macrophages from lipid peroxidation and induces a Keap1/Nrf2/ ARE-dependent antioxidant response. Life Sci. 166, 100-107 https://doi.org/10.1016/j.lfs.2016.10.013

Chen JH, Chou CC (2015): Acrylamide inhibits cellular differentiation of human neuroblastoma and glioblastoma cells. Food Chem. Toxicol. 82, 27-35 https://doi.org/10.1016/j.fct.2015.04.030

Clement FC, Dip R, Naegeli H (2007): Expression profile of human cells in culture exposed to glycidamide, a reactive metabolite of the heat-induced food carcinogen acrylamide. Toxicology 240, 111-124 https://doi.org/10.1016/j.tox.2007.07.019

Dearfield KL, Abernathy CO, Ottley MS, Brantner JH, Hayes PF (1988): Acrylamide: its metabolism, developmental and reproductive effects, genotoxicity, and carcinogenicity. Mutat. Res. 195, 45-77 https://doi.org/10.1016/0165-1110(88)90015-2

Devi KP, Rajavel T, Habtemariam S, Nabavi SF, Nabavi SM (2015): Molecular mechanisms underlying anticancer effects of myricetin. Life Sci. 142, 19-25 https://doi.org/10.1016/j.lfs.2015.10.004

Dobrovolsky VN, Pacheco-Martinez MM, McDaniel LP, Pearce MG, Ding W (2016): In vivo genotoxicity assessment of acrylamide and glycidyl methacrylate. Food Chem. Toxicol. 87, 120-127 https://doi.org/10.1016/j.fct.2015.12.006

Eulenfeld R, Dittrich A, Khouri C, Müller PJ, Mütze B, Wolf A, Schaper F. (2012): Interleukin-6 signalling: more than JAKS and STATs. Eur. J. Cell Biol. 91, 486-495 https://doi.org/10.1016/j.ejcb.2011.09.010

Ghanayem BI, Witt KL, El-Hadri L, Hoffler U, Kissling GE, Shelby MD, Bishop JB (2005a): Comparison of germ cell mutagenicity in male CYP2E1-null and wild-type mice treated with acrylamide: evidence supporting a glycidamide-mediated effect. Biol. Reprod. 72, 157-163

https://doi.org/10.1095/biolreprod.104.033308

Ghanayem BI, McDaniel LP, Churchwell MI, Twaddle NC, Snyder R, Fennell TR, Doerge DR (2005b): Role of CYP2E1 in the 
epoxidation of acrylamide to glycidamide and formation of DNA and hemoglobin adducts. Toxicol. Sci. 88, 311-318 https://doi.org/10.1093/toxsci/kfi307

He FS, Zhang SL, Wang HL, Li G, Zhang ZM, Li FL, Dong XM, Hu FR (1989): Neurological and electroneuromyographic assessment of the adverse effects of acrylamide on occupationally exposed workers. Scand. J. Work Environ. Health 15, 125-129 https://doi.org/10.5271/sjweh.1878

Hu Y, Dong XZ, Liu X, Liu P, Chen YB (2016): Enhanced antitumor activity of cetuximab in combination with the Jak inhibitor CYT387 against non-small-cell lung cancer with various genotypes. Mol. Pharmaceut. 13, 689-697 https://doi.org/10.1021/acs.molpharmaceut.5b00927

Hwangbo W, Lee LH, Ahn S, Kim S, Park KH, Kim CH, Kim I (2013): EGFR gene amplification and protein expression in invasive ductal carcinoma of the breast. Korean J. Pathol. 47, $107-115$ https://doi.org/10.4132/KoreanJPathol.2013.47.2.107

Kelekar A, Thompson CB (1998): Bcl-2-family proteins: the role of the BH3 domain in apoptosis. Trends Cell Biol. 8, 324-330 https://doi.org/10.1016/S0962-8924(98)01321-X

Kim KH, Park B, Rhee DK, Pyo S (2015): Acrylamide Induces Senescence in Macrophages through a Process Involving ATF3, ROS, p38/JNK, and a Telomerase-Independent Pathway. Chem. Res. Toxicol. 28, 71-86 https://doi.org/10.1021/tx500341z

Klein HL (2008): The consequences of Rad51 overexpression for normal and tumor cells. DNA Repair. 7, 686-693 https://doi.org/10.1016/j.dnarep.2007.12.008

Korsmeyer SJ, Shutter JR, Veis DJ, Merry DE, Oltvai ZN (1993): Bcl-2/Bax: a rheostat that regulates an anti-oxidant pathway and cell death. Semin. Cancer Biol. 4, 327-332

Lakshmi D, Gopinath K, Jayanthy G, Anjum S, Prakash D, Sudhandiran G (2012): Ameliorating effect of fish oil on acrylamide induced oxidative stress and neuronal apoptosis in cerebral cortex. Neurochem. Res. 37, 1859-1867 https://doi.org/10.1007/s11064-012-0794-1

Lee T, Manjanatha MG, Aidoo A, Moland CL, Branham WS, Fuscoe JC, Ali AA, Desai VG (2012): Expression analysis of hepatic mitochondria-related genes in mice exposed to acrylamide and glycidamide. J. Toxicol. Env. Heal A. 75, 324-339 https://doi.org/10.1080/15287394.2012.668160

Lu CH, Lin SC, Yang SY, Pan MY, Lin YW, Hsu CY, Wei YH, Chang JS, Chang CC (2012): Prodigiosin-induced cytotoxicity involves RAD51 down-regulation through the JNK and p38 MAPK pathways in human breast carcinoma cell lines. Toxicol. Lett. 212, 83-89 https://doi.org/10.1016/j.toxlet.2012.05.002

Manjanatha MG, Aidoo A, Shelton SD, Bishop ME, McDaniel LP, Lyn-Cook LE, Doerge DR (2006): Genotoxicity of acrylamide and its metabolite glycidamide administered in drinking water to male and female Big Blue mice. Environ. Mol. Mutagen. $47,6-17$ https://doi.org/10.1002/em.20157

Ono M, Kuwano M (2006): Molecular mechanisms of epidermal growth factor receptor (EGFR) activation and response to gefitinib and other EGFR-targeting drugs. Clin. Cancer Res. 12, 7242-7251
https://doi.org/10.1158/1078-0432.CCR-06-0646

Pardhasaradhi B, Ali A, Kumari A, Reddanna P, Khar A (2003): Phycocyanin-mediated apoptosis in AK-5 tumor cells involves down-regulation of $\mathrm{Bcl}-2$ and generation of ROS. Mol. Cancer Ther. 2, 1165-1170

Reuter S, Gupta SC, Chaturvedi MM, Aggarwal BB (2010): Oxidative stress, inflammation, and cancer: how are they linked. Free Radic. Biol. Med. 49, 1603-1616 https://doi.org/10.1016/j.freeradbiomed.2010.09.006

Shan X, Li Y, Meng X, Wang P, Jiang P, Feng Q (2014): Curcumin and (-)-epigallocatechin-3-gallate attenuate acrylamideinduced proliferation in HepG2 cells. Food Chem. Toxicol. 66, 194-202 https://doi.org/10.1016/j.fct.2014.01.046

Shen J, Qiu X, Jiang B, Zhang D, Xin W, Fung P, Zhao B (2003): Nitric oxide and oxygen radicals induced apoptosis via bcl-2 and p53 pathway in hypoxia-reoxygenated cardiomyocytes. Sci. China Ser. C. 46, 28-39 https://doi.org/10.1007/BF03182682

Solomon JJ, Fedyk J, Mukai F, Segal A (1985): Direct alkylation of 2'-deoxynucleosides and DNA following in vitro reaction with acrylamide. Cancer Res. 45, 3465-3470

Sun Y, Han Y, Wang X, Wang W, Wang X, Wen M, Xia J, Xing H, Li X, Zhang Z (2016): Correlation of EGFR Del 19 with Fn14/ JAK/STAT signaling molecules in non-small cell lung cancer. Oncol. Rep. 36, 1030-1040 https://doi.org/10.3892/or.2016.4905

Takaku M, Kainuma T, Ishida-Takaku T, Ishigami S, Suzuki H, Tashiro S, van Soest RWM, Nakao Y, Kurumizaka H (2011): Halenaquinone, a chemical compound that specifically inhibits the secondary DNA binding of RAD51. Genes Cells 16, 427-436 https://doi.org/10.1111/j.1365-2443.2011.01494.x

Tareke E, Rydberg P, Karlsson P, Eriksson S, Tornqvist M (2002): Analysis of Acrylamide, a Carcinogen Formed in Heated Foodstuffs. J. Agric. Food Chem. 50, 4998-5006 https://doi.org/10.1021/jf020302f

Venkatakrishnan K, Von MLL, Greenblatt DJ (2001): Human drug metableolism and the cytochromes P450: application and relevance of in vitro models. J. Clin. Pharm. 11, 1149-1179 https://doi.org/10.1177/00912700122012724

Vogler M, Dinsdale D, Dyer MJ, Cohen GM (2009): Bcl-2 inhibitors: small molecules with a big impact on cancer therapy. Cell Death Differ. 16, 360-367 https://doi.org/10.1038/cdd.2008.137

Von Tungeln LS, Doerge DR, da Costa GG, Marques MM, Witt WM, Koturbash I, Pogribny IP, Beland FA (2012): Tumorigenicity of acrylamide and its metabolite glycidamide in the neonatal mouse bioassay. Int. J. Cancer 131, 2008-2015 https://doi.org/10.1002/ijc.27493

Waga S, Hannon G, Beach D, Stillman B (1994): The P21 WAF1 inhibitor of cyclin-dependent kinases controls DNA replication by interaction with PCNA. Nature 369, 574-578 https://doi.org/10.1038/369574a0

Wang ET, Chen DY, Liu HY, Yan HY, Yuan Y (2015): Protective effect of allicin against glycidamide-induced toxicity in male and female mice. Gen. Physiol. Biophys. 34, 177-187 doi:10.4149/ gpb_2014038 https://doi.org/10.4149/gpb_2014038 
Wang L, Hu T, Shen J, Zhang L, Li LF, Chan RL, Li MX, Wu WK, Cho CH (2016): Miltirone induced mitochondrial dysfunction and ROS-dependent apoptosis in colon cancer cells. Life Sci. 151, 224-234 https://doi.org/10.1016/j.lfs.2016.02.083

Zhang XY, Liu ZJ, Xu B, Sun ZL, Gong YQ, Shao CS (2012): Neferine, an alkaloid ingredient in lotus seed embryo, inhibits proliferation of human osteosarcoma cells by promoting p38 MAPKmediated p21 stabilization. Eur. J. Pharmacol. 677, 47-54 https://doi.org/10.1016/j.ejphar.2011.12.035

Zhao M, Wang P, Zhu Y, Liu X, Hu X, Chen F (2015): Blueberry anthocyanins extract inhibits acrylamide-induced diverse toxicity in mice by preventing oxidative stress and cytochrome P450 2E1 activation. J. Funct. Foods 14, 95-101 https://doi.org/10.1016/j.jff.2015.01.035

Received: January 18, 2017

Final version accepted: July 26, 2017 